\title{
EVALUATION OF WATER SAVING MEASURES FOR MID-SIZED TOURIST LODGING UNITS: THE CASE OF SAMOS ISLAND, GREECE
}

\author{
ELEFTHERIA E. KLONTZA ${ }^{1}$, ELENI KAMPRAGKOU ${ }^{1}$, \\ KONSTANTINOS VERVERIDIS ${ }^{1}$, MARIA P. PAPADOPOULOU ${ }^{2}$, \\ and DEMETRIS F. LEKKAS ${ }^{1, *}$
}

\author{
${ }^{1}$ Analysis and Simulation of Environmental Systems Research Group, School of Science, University of Aegean, 83200 Karlovasi, Greece \\ 2 Physical Geography and Environmental Impacts Lab, School of Rural \& Surveying Engineering, National Technical University \\ of Athens, Greece \\ *Corresponding author: dlekkas@env.aegean.gr
}

\begin{abstract}
Hotel sector causes significant environmental stress in both natural and built up areas due to their consumption of water and energy. In addition, the production of large volumes of liquid and solid waste results in a significant environmental footprint. The use of water and energy by hotels is strongly linked (e.g. energy is consumed for hot water, operation of the pool, preparation of meals, etc.) and usually referred to as the water - energy nexus. Thus, for big consumers like hotels, water and energy consumption should be addressed collectively as water-saving measures can lead to a reduction in energy consumption. The aim of this study is to assess the environmental performance of mid-sized hotel units by analyzing and quantifying their use of water. An analysis using a two-step approach was made of 8 accommodation facilities located on Samos Island, Greece: (i) a mapping of water use by adopting an end-use approach, and then (ii) an assessment of saving practices using three main criteria: savings, cost of investment and payback time. The preliminary results indicate that for small sized lodging units, water consumed inside the guest rooms accounts for the majority of all the water used and low-cost water saving measures and actions can reduce the pressure on water resources without disturbing guests, while increasing the financial profitability of a hotel.
\end{abstract}

Keywords: tourist lodging mid-sized units, water uses, saving potential, Samos Island

doi: $10.14712 / 23361964.2016 .7$

\section{Introduction}

More than $30 \%$ of international tourist destinations are located within the Mediterranean basin, which makes it among the most popular of tourist areas globally. The tourist industry in the Mediterranean region has traditionally been characterized by strong seasonality, with large variations in occupancy rates between winter and summer. Climatic factors, such as temperature, sunshine hours and precipitation mainly determine the flow of international tourism within Europe, which impose tremendous pressures on the natural resources of a region (Amelung and Viner 2006). In 2007, Bohdanowicz and Martina conducted a survey of a large number of Hilton International and Scandic Europe hotels in order to establish energy and water consumption benchmarks and classify them. In order to obtain representative indicators, components such as brand name, hotel standards, resource management, environmental performance, location, and climate conditions were considered. In addition, water management based on reducing-reusing-reaching-recycling approaches (Kasim et al. 2014) and a tourism environmental composite indicator TECI (Michailidou et al. 2015) were recently developed to propose good practices for hotel managers on how different sized hotel units could implement various water savings measures that they were intellectually and technologically capable of.
Lodging operations can be characterized as successful and efficient as long as they provide the right mix of characteristics to attract and retain guests. Two decades ago, the lodging factors considered to determine the quality of a tourist lodging unit, were primarily: facility features, room amenities, housekeeping, security and food-service operation (Griffin 1998). Nowadays, a significant portion of the potential visitors are looking for something that will improve their hotel stay by providing top-level environmental-friendly services.

Mass tourism activities and lodging units can lead to degradation of the natural environment by putting pressure on vulnerable natural resources such as water and soil. Crete, Rhodes and Corfu are among the most wellknown tourist destinations in Greece, where large sized tourist units are operating to accommodate the increased loads mainly during summer. On the other hand, in most small and recently developed tourist areas like the Greek islands in the Aegean Sea, local businesses are attempting to reduce the negative social-economic and environmental effects of mass tourism by promoting actions that will increase the added value of their local tourist product. For this reason, small and mid-sized tourist lodging units are encouraged by the local commercial and tourist chambers to invest in high quality tourist services in order to increase their environmental profile for those tourist groups that are interested in knowing the significant advantages of the local physical and cultural

Klontza, E. E., Kampragkou, E., Ververidis, K., Papadopoulou, M. P., Lekkas, D. F.: Evaluation of water saving measures for mid-sized tourist lodging units: the case of Samos Island, Greece European Journal of Environmental Sciences, Vol. 6, №. 1, pp. 37-42 (c) 2016 Charles University in Prague. This is an open-access article distributed under the terms of the Creative Commons Attribution License (http://creativecommons.org/licenses/by/4.0). 
environment. Therefore, the successful implementation of water saving practices in small sized hotels should be encouraged since it contributes to tourism sustainability (Barberan et al. 2013) and could attract specific groups of tourists that are willing to pay more for eco-friendly facilities.

Exploitation of the energy saving potential of hotel infrastructures usually requires a large investment, however, wherever advanced Energy Efficiency Measures (EEMs) have been implemented, there have been significant energy savings (Chedwal et al. 2015). Interventions related to energy saving equipment and use of renewable energy sources are among the practices that tourists are increasingly looking for and are willing to pay for in hotels (Tsagarakis et al. 2011). Efficiency in water consumption is an important factor in the evaluation of hotel sustainability; however, it still of low priority. Barberan et al. (2013) show that a small investment in water saving practices could lead to a significant reduction in water consumption and its associated operating costs. In most of the energy-consuming activities in a hotel (e.g. swimming pool, meal preparations, laundry), water is also used, so the water-saving measures can lead to energy saving as well.

In this paper, an analysis of the water saving potential of lodging units is attempted. The approach includes the following steps:

(i) mapping of water use by adopting an end-use approach,

(ii) assessment of saving practices using three main criteria: savings, cost of investment and payback time.

The large number of activities taking place in a hotel that increase water consumption were taken into account, in order to provide hotel owners and managers with a detailed picture of their current water consumption. By applying a tool that calculates the reduction in the operational cost after the implementation of water saving measures, a clear view of the economic benefits of investing in water and energy efficiency was obtained.

\section{Methodological Approach}

The analysis focused on eight mid-sized lodging units, located on the island of Samos in Greece. This type of accommodation is very common on Greek islands. They are primarily small family businesses that appeal to medium-income tourists as they offer high quality services mainly benefiting from the natural environment and the cultural heritage of Greece. In order to enhance their environmental image, the units analyzed expressed an interest in investing in rational water management, which will reduce their operating costs and enhance their environmental image. The "unit use" approach (Froukh 2001; Davis 2003) is used to estimate water demand, using Eq. 1 and Eq. 2:

$$
\begin{aligned}
& Q=\sum_{u=1}^{n} q_{u, t} N_{u, t} \\
& q_{u, t}=\sum_{i=1}^{m} f_{i, t} T_{i, t} c_{i, t}
\end{aligned}
$$

Where:

$Q$ is total water demand,

$q_{u, t}$ is average water used per unit and time for a specific use $(u)$ at a specific time $(t)$,

$N_{u, t}$ is number of units used at time $t$,

$f_{i, t}$ is frequency with which the appliance $i$ is used per day,

$T_{i, t}$ is average time for which the appliance $\mathrm{i}$ is used per day,

$c_{i, t}$ is consumption of appliance $\mathrm{i}$ in terms of liters of water per day.

Water demand includes four main water uses: (i) hosting customers, (ii) pool, (iii) garden irrigation, and (iv) other services and uses (washing of towels/linen, cleaning, use of employees and visitors, preparing light meals). The estimates are based on water use devices that are already installed in a lodging unit and their use (frequency). Water leakages are also taken into account in order to have a more representative estimate of water demand. The list of the data needed for this analysis is in Table 1.

Table 1 List of the data needed for estimating the water demand of hotels.

\begin{tabular}{|l|l|}
\hline \multirow{4}{*}{$\begin{array}{l}\text { Unit } \\
\text { characteristics }\end{array}$} & $\begin{array}{l}\text { - Unit type (hotel, apartment, villa) } \\
- \text { Number of rooms } \\
\text { - Number of beds } \\
\text { washing) } \\
- \text { Garden features } \\
- \text { Number of employees } \\
- \text { Number of visitors }\end{array}$ \\
\hline Occupancy & $\begin{array}{l}- \text { Number of beds (monthly) } \\
- \text { Number of nights (monthly) }\end{array}$ \\
\hline Water & $\begin{array}{l}- \text { Pool capacity } \\
\text { equipment }\end{array}$ \\
& $\begin{array}{l}\text { Irrigation system } \\
- \text { Equipment type and frequency of use }\end{array}$ \\
\hline Related costs & $\begin{array}{l}\text { - Tiered water invoice } \\
- \text { Pricing of sewerage services (fixed fee, } \\
\text { a percentage of the value of water consumed) }\end{array}$ \\
\hline
\end{tabular}

For the purpose of this analysis, an application tool was developed that took into consideration the water saving technologies and operation options (Table 2) that could be easily implemented in a mid-sized lodging unit. The analysis involves four steps:

- Step 1 "Mapping of water uses": Data entry concerning the type of facility, number of visitors, existing appliances, frequency of use, etc.

- Step 2 "Estimation of water demand": Monthly and annual water demand for the four main water use categories (hosting customers, pool, garden irrigation, other services and uses). 
- Step 3 "Selection of water saving options": Selection of water saving technologies and options and data entry concerning their cost.

- Step 4 "Comparative assessment of water saving options": Assessment of each technology using three criteria: (i) water saving potential, (ii) water cost reduction, and (iii) payback time.

Table 2 List of water saving technologies available for each of the water uses in a lodging unit.

\begin{tabular}{|l|l|}
\hline $\begin{array}{l}\text { Hosting } \\
\text { customers }\end{array}$ & $\begin{array}{l}\text { - Use of dual flash toilets } \\
\text { - Use of low flow appliances } \\
\text { - Use of recycled water in the toilet } \\
\text { - Leakage control }\end{array}$ \\
\hline Pool & - Filling with sea water \\
\hline \multirow{3}{*}{ Garden } & $\begin{array}{l}\text { - Change from irrigation to efficient technologies } \\
\text { - Rainwater harvesting for irrigation } \\
\text { - Use of recycled water for irrigation }\end{array}$ \\
\hline \multirow{3}{*}{ Other services } & $\begin{array}{l}\text { - Replacement of linen every three days } \\
\text { - Replacement of washing machines with water } \\
\text { and energy efficient appliances } \\
\text { - Use of dual flash toilets } \\
\text { - Use of low flow appliances }\end{array}$ \\
\hline
\end{tabular}

\section{Test application}

The water use profile of eight accommodation facilities (seven hotels and one block of apartments) was analyzed. Four of them operated on a seasonal basis (May to October) and the other four on an annual basis. Most of the units ( 5 out of 8 ) are small-medium with less than 60 rooms. The services provided include breakfast (7 out of 8 units), pool ( 8 out of 8 units), linen washing in the unit ( 8 out of 8 units) and hosting events and meetings (5 out of 8 units). Seven of the units have an irrigated garden.

The data collected for 2015 were analyzed (i.e. occupancy, number of employees, water equipment), whereas the values of specific parameters were obtained from national legislation (e.g. irrigation requirements per type of plant, irrigation efficiency, Source: JMD F16/6631/89) or the literature (e.g. water use rates of appliances, water demand of different type of washing machine, source: www .watersave.gr). The parameter values used in the calculations are presented in Table 3.

Table 3 Water consumption of a hotel when operational (typical values).

\begin{tabular}{|l|c|c|}
\hline $\begin{array}{l}\text { Irrigation method } \\
\text { Source: JMD F } \\
\mathbf{1 6 / 6 6 3 1 / 8 9}\end{array}$ & Efficiency & \\
\hline Inundation & 0.70 & \\
\hline Sprinklers & 0.85 & \\
\hline Furrow & 0.68 & \\
\hline Drip & 0.94 & \\
\hline & Water consumption & \\
\hline Vegetation & (m $\mathbf{3} /$ day) & ( $^{\mathbf{3}} /$ week $)$ \\
\hline & 0.008 & 0.0056 \\
\hline Lawn & & \\
\hline
\end{tabular}

\begin{tabular}{|c|c|c|}
\hline Bush & 0.004 & 0.008 \\
\hline \multirow{2}{*}{ Trees } & 0.016 & 0.016 \\
\hline & $\begin{array}{l}\text { Washing machine } \\
\text { (liters/kg of linen) }\end{array}$ & $\begin{array}{c}\text { Dishwasher } \\
\text { (liters/per cycle) }\end{array}$ \\
\hline Economy & 7 & 20 \\
\hline Medium & 10 & 30 \\
\hline Large & 12 & 40 \\
\hline Appliance & Type & value \\
\hline \multirow[t]{2}{*}{ Shower } & High flow $\left(I \min ^{-1}\right)$ & 15 \\
\hline & Low flow (liters/flush) & 6 \\
\hline \multirow[t]{2}{*}{ Toilet flush } & Single flush (I $\left.\min ^{-1}\right)$ & 9 \\
\hline & Double flush (I $\left.\mathrm{min}^{-1}\right)$ & 6 \\
\hline \multirow[t]{2}{*}{ Sink tap } & High flow $\left(\mathrm{min}^{-1}\right)$ & 10 \\
\hline & Low flow $\left(I \mathrm{~min}^{-1}\right)$ & 5 \\
\hline \multirow[t]{2}{*}{ Bathroom tap } & High flow $\left(\mathrm{min}^{-1}\right)$ & 12 \\
\hline & Low flow $\left(I \mathrm{~min}^{-1}\right)$ & 7 \\
\hline \multirow[t]{2}{*}{ Kitchen sink tap } & High flow $\left(I \mathrm{~min}^{-1}\right)$ & 8 \\
\hline & Low flow (I min $\left.{ }^{-1}\right)$ & 6 \\
\hline \multicolumn{3}{|l|}{$\begin{array}{l}\text { Water consumption } \\
\text { for breakfast prepa- } \\
\text { ration (I/guest/day) }\end{array}$} \\
\hline Breakfast preparation & 10 & \\
\hline $\begin{array}{l}\text { Breakfast preparation } \\
\text { and washing }\end{array}$ & 15 & \\
\hline
\end{tabular}

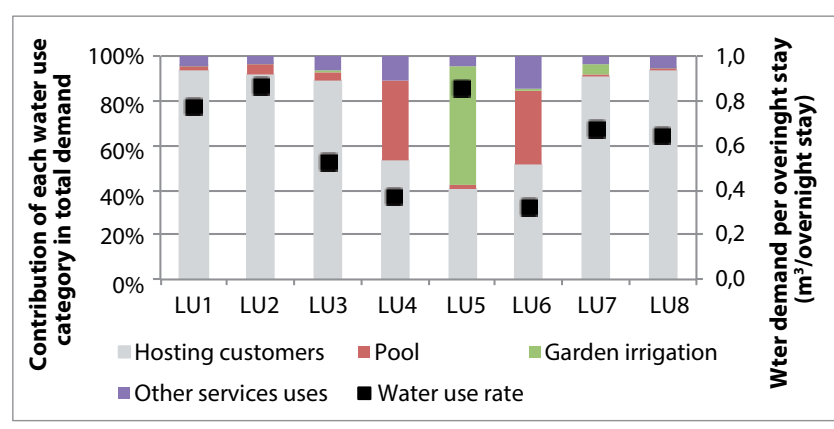

Fig. 1 Water use prolife of the accommodation units examined.

In Fig. 1 the water use profile of the hotel units selected is presented. As has been estimated from the collected data (Step 2: estimation of water demand), water use rates per overnight stay are in the range of 0.32 to $0.86 \mathrm{~m}^{3} /$ overnight stay. In six out of eight units the average water use rate exceeds $0.40 \mathrm{~m}^{3}$ /overnight stay, which is a typical average for tourism (Gössling et al. 2012), while the lowest water use rate was estimated for establishments that have already installed low flow and water efficient appliances. May is the month with the highest water demand as is that month that the pools are filled with water. 
Results indicate that the water use profile of the units investigated is well represented by the difference between the actual (measured) and estimated water use, which is small and ranges from $1.1 \%$ to $5.3 \%$. In order to assess the water saving potential of the twenty water saving measures, which are described below, they were included in the calculation tool and analyzed:

- Hosting customers component

1. Replacement of the regular shower heads with water saving systems

2. Replacement of regular taps with water saving systems - bathroom sink

3. Use of a flow controller on the taps - bathroom sink

4. Replacement of regular taps with water saving systems - bathroom tap

5. Replacement of existing units with dual flushing toilets

6. Leakage control

7. Recycle of water for toilet use

- Pool

8. Use of sea water in the swimming pool

- Garden irrigation

9. Change the irrigation method (drip irrigation) grass

10. Change the irrigation method (drip irrigation) bush

11. Change the irrigation method (drip irrigation) tree

12. Rainwater harvesting for irrigation

13. Recycle water for irrigation

- Other services and water uses

14. Use towels for more than one day

15. Use the same bed linen for three days

16. Washing machine replacement

17. Dish washer replacement

18. Replacement of regular taps with water saving systems - bathroom sink

19. Use of a flow controller on the taps - bathroom sink

20. Replacement of the existing units with dual flush toilets

Table 4 Characteristics of two of the lodging units in the sample.

\begin{tabular}{|l|c|c|}
\hline Hotel ID & LU6 & LU7 \\
\hline Operation & $\begin{array}{c}\text { Seasonal } \\
\text { (May-October) }\end{array}$ & Annual \\
\hline Number of rooms & 43 & 46 \\
\hline Number of employees & 11 & 8 \\
\hline Annual value of overnight stays & 5563 & 15000 \\
\hline Pool size (m³) & 600 & 100 \\
\hline Garden - lawn (area) & No & Yes $\left(300 \mathrm{~m}^{2}\right)$ \\
\hline Garden - trees \& bushes (number) & 18 & 19 \\
\hline Irrigation efficiency & 0.7 & 0.7 \\
\hline Linen washing & Yes & Yes \\
\hline
\end{tabular}

European Journal of Environmental Sciences, Vol. 6, №. 1

\begin{tabular}{|l|c|c|}
\hline $\begin{array}{l}\text { Use of low flow/water saving } \\
\text { appliances }\end{array}$ & Yes & No \\
\hline $\begin{array}{l}\text { Estimated water use rate } \\
\text { (m³/overnight stay) }\end{array}$ & 0.32 & 0.67 \\
\hline
\end{tabular}

The characteristics of the two lodging units that were sampled (lodgings) in this study are presented in Table 4 .

Table 5 presents the water saving potential of the technologies tested. The range of values represent the differences in the water use profile and the type of appliances that are already being used in each lodging unit. As expected, there is a significant reduction in water demand by improving water use efficiency for hosting customers (in the rooms) and garden irrigation.

Table 5 Water saving potential per water saving technology.

\begin{tabular}{|l|c|c|c|}
\hline $\begin{array}{l}\text { Water saving } \\
\text { technology }\end{array}$ & $\begin{array}{c}\text { Saving } \\
\text { potential (\%) }\end{array}$ & $\begin{array}{c}\text { Water saving } \\
\text { technology }\end{array}$ & $\begin{array}{c}\text { Saving } \\
\text { potential (\%) }\end{array}$ \\
\hline M1 & 10.537 to 21.423 & M11 & 0.004 to 0.061 \\
\hline M2 & 6.885 to 26.414 & M12 & 0.019 to 26.570 \\
\hline M3 & 2.754 to 10.565 & M13 & 0.019 to 26.570 \\
\hline M4 & 2.738 to 15.869 & M14 & 0.008 to 0.062 \\
\hline M5 & 1.773 to 3.562 & M15 & 0.018 to 0.137 \\
\hline M6 & 5.000 to 5.100 & M16 & 0.112 to 3.051 \\
\hline M7 & 2.659 to 5.564 & M17 & 0.037 to 0.075 \\
\hline M8 & 0.681 to 33.342 & M18 & 0.119 to 1.106 \\
\hline M9 & 0.864 to 9.372 & M19 & 0.068 to 0.632 \\
\hline M10 & 0.001 to 0.052 & M20 & 0.171 to 1.581 \\
\hline & & & \\
\hline
\end{tabular}

Fig. 2 presents the average values and range of savings expressed in Euros obtained by using the different water saving technologies. Differences are attributed to different water use profiles and technologies for each lodging unit. It should be noted that even though M12 and M13 result in similar reductions in the water bill, the payback time is different as the cost for the implementation of each technology varies. As a result, M12 has a significantly lower payback time ( $\sim 5$ times less).

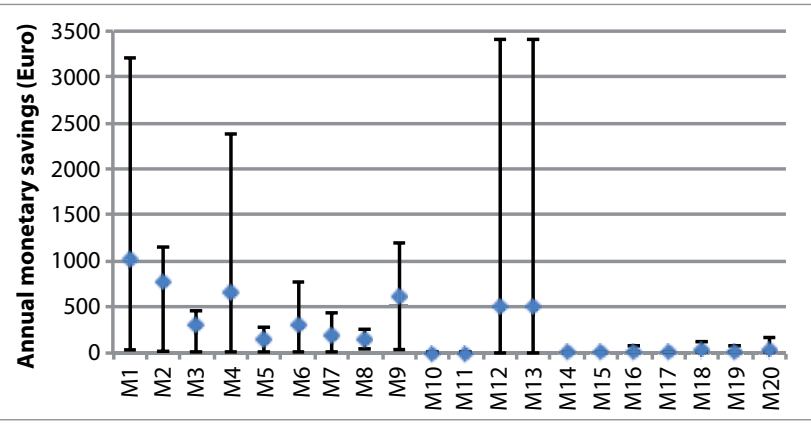

Fig. 2 Water use prolife of the accommodation units examined

Finally, in Fig. 3 is the predicted water demand of the two lodging units if they used the different water saving measures. 


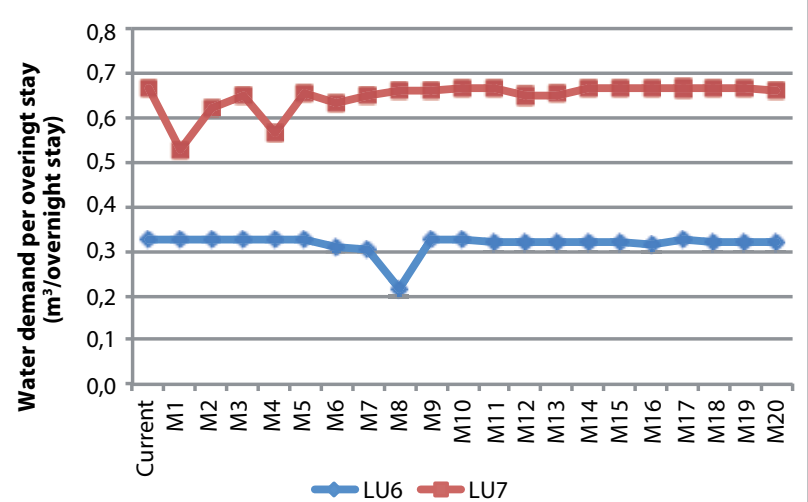

Fig. 3 Water demand per overnight stay in the two lodging units when using the different water saving measures.

\section{Discussion and Conclusions}

In this paper, a preliminary analysis of the water saving potential of a group of mid-sized lodging units was carried out in order to define the water uses that mainly contribute to their water consumption and provide an insight for hotel managers of the benefits associated with environmental friendly practices. A clear understanding of the consumption profile of each unit was obtained, which is determined by the geographical location and climate in the region.

Even though the results are only for a small group of units, there are several conclusions that can be drawn. For this type of lodging unit, guest rooms (hosting services) are the main water-consuming factor, which is contrary to Gössling et al. (2012) conclusion, who report that the main water-consuming factors, in general, are irrigated gardens, swimming pools, spa and sports facilities, golf courses, cooling towers (if any), guest rooms and kitchens. This is possibly due to the fact that even though most of the units investigated have gardens, they are relatively small compared to those of most large hotels. Another important finding is the fact that a significant reduction in water consumption can be achieved by using sea water instead of freshwater in the swimming pools. This is a practice that is not typical in Greece but could result in significant savings and reduction in the demand for water on the islands. Summarizing, the presented results are in accordance with those of Barberan et al. (2013), who propose that investment in low cost water savings measures and actions can reduce the consumption of water without inconveniencing guests while increasing the financial profitability of a hotel.

The Eastern Mediterranean is among the most vulnerable regions in terms of the increase in water consumption associated with the increase in tourism in time and space, which is putting a tremendous strain on domestic fresh water supplies and infrastructure. In popular tourist resorts, it is especially important to estimate both di- rect and indirect water consumption in order to achieve a sustainable consumption (Hadjikakou et al. 2013). In places where the main fresh water resource is groundwater (Gatt and Schranz 2015), as on islands like Malta, Crete and Cyprus, additional efforts should be made to use water in a sustainable way.

\section{Acknowledgements}

This research was funded by the project The University of the Aegean, the prominent and driving factor for the economic and social growth of the wide Aegean area of the Operational Programme "Education and Lifelong Learning", which is co-funded by the European Union (European Social Fund) and National Resources.

\section{REFERENCES}

16/6631/89 JMD titled Determination of minimum and maximum limits of necessary quantities for the rational use of water in irrigation.

Amelung B, Viner D (2006) Mediterranean Tourism: Exploring the Future with the Tourism Climatic Index. J Sustain Tour 14: 349-366.

Barberan R, Egea P, Gracia-de-Renteria P, Salvador M (2013) Evaluation of water saving measures in hotels: A Spanish case study. Int J Hosp Manag 34: 181-191.

Bohdanowicz P, Martinac I (2007) Determinants and benchmarking of resource consumption in hotels - Case study of Hilton International and Scandic in Europe. Energ Buildings 39: 82-95.

Chedwal R, Mathur J, Das Agarwal G, Dhaka S (2015) Energy saving potential through Energy Conservation Building Code and advance energy efficiency measures in hotel buildings of Jaipur City, India. Energ Buildings 92: 282-295.

Davis W (2003) Water Demand Forecast Methodology for California Water Planning Areas - Work Plan and Model Review. California Bay-Delta Authority.

Froukh M (2001) Decision-Support System for Domestic Water Demand Forecasting and Management. Water Resources Management. doi: 10.1023/A:1015527117823.

Gatt K, Schranz C (2015) Retrofitting a 3 star hotel as a basis for piloting water minimization interventions in the hospitality sector. Int J Hosp Manag 50: 115-121.

Gössling S, Peeters P, Hall MC, Ceron J-P, Dubois G, Lehmann LV, Scott D (2012) Tourism and water use: Supply, demand and security. An international review. Tourism Manage 33: 1-15.

Griffin RK (1998) Small lodging operations in Costa Rice: A case study, Cornell Hotel and Restaurant Adminstation Quartely, pp. 55-63.

Hadjikakou M, Chenoweth J, Miller G (2013) Estimating the direct and indirect water use of tourism in the eastern Mediterranean. J Environ Manage 114: 548-556.

Han H, Hsu LT, Lee JS (2009) Empirical investigation of the roles of attitudes toward green behaviors, overall image, gender, and age in hotel costumers' eco-friendly decision-making process. Int J Hosp Manag 28: 519-528.

http://www.watersave.gr (Accessed March 2016). 
Kasim A, Gursoy D, Okumus F, Wong A (2014) The importance of water management in hotels: a framework for sustainability through innovation. J Sustain Tour. doi: 10.1080/ 09669582.2013.873444.

Michailidou AV, Vlachokostas C, Moussiopoulos N (2015) A methodology to assess the overall environmental pressure attributed to tourism areas: A combined approach for typical all-sized hotels in Chalkidiki, Greece. Ecol Indic 50: 108-119.

Tsagarakis K, Bounialetou F, Gillas K, Profylienou M, Pollaki A, Zografakis N (2011) Tourists' attitudes for selecting accommodation with investments in renewable energy and energy saving systems. Renew Sust Energ Rev 15: 1335-1342. 